\title{
Avaliação da contaminação microbiana em produtos desinfetantes de uso geral
}

\author{
Microbial contamination in household disinfectant products
}

RIALA6/1560

\author{
Rodrigo Rollin PINHEIRO ${ }^{1 *}$, Bruna Peres SABAGH ${ }^{1}$, Livia Maria Rubem VIDAL ${ }^{2}$, João Flávio \\ Carneiro VERAS ${ }^{2}$, Verônica Viana VIEIRA ${ }^{2}$, Aline da Silva Soares SOUTO ${ }^{3}$, Daniela Cristina Rodrigues \\ PEREIRA $^{1}$, Marta de Campos NEVES ${ }^{1}$, Maria Helena Simões VILLAS BOAS ${ }^{1}$ \\ *Endereço para Correspondência ${ }^{1}$ Setor de Saneantes, Departamento de Microbiologia, Instituto Nacional de Controle de \\ Qualidade em Saúde, Fundação Oswaldo Cruz, Av Brasil 4365, 21040-900, Rio de Janeiro, Brazil. Tel.: 55-21-38655174, +55- \\ 21-38655103; fax: +55-21-22900915. E-mail: rodrigorollin@gmail.com. \\ ${ }^{2}$ Setor de Identificação Bacteriana, Departamento de Microbiologia, Instituto Nacional de Controle de Qualidade em Saúde, \\ Fundação Oswaldo Cruz, Rio de Janeiro, Brasil. \\ ${ }^{3}$ Setor de Fungos de Referência, Departamento de Microbiologia, Instituto Nacional de Controle de Qualidade em Saúde, \\ Fundação Oswaldo Cruz, Rio de Janeiro, Brasil. \\ Recebido: 11.12.2012 - Aceito para publicação: 11.06.2013
}

\section{RESUMO}

Em vista de um estudo desenvolvido no Setor de Saneantes do Instituto Nacional de Controle de Qualidade em Saúde da Fundação Oswaldo Cruz, referente à avaliação da atividade antimicrobiana de desinfetantes, no presente trabalho foram analisados produtos desinfetantes de uso geral disponíveis no mercado brasileiro. Os desinfetantes foram coletados aleatoriamente, dos quais três (produtos A, B e C), apresentaram contaminação microbiana. Para efetuar o isolamento e a identificação dos microrganismos contaminantes foram utilizados o aparelho $\operatorname{Vitek}^{\circledR} 2$, a amplificação e o sequenciamento do gene rRNA 16S. A análise realizada por meio de $\operatorname{Vitek}^{\circledast} 2$ revelou a presença das bactérias Serratia marcescens e Achromobacter xylosoxidans, respectivamente, nos produtos A e B. No produto C foram detectadas Aeromonas salmonicida pelo Vitek ${ }^{\circledast} 2$ e Burkholderia lata pela técnica de amplificação da reação em cadeia da polimerase.

Palavras-chave. contaminação microbiana, desinfetantes, controle de qualidade, vigilância sanitária.

\begin{abstract}
On account of a study developed in Sanitation Sector at the National Institute of Quality Control in Health of Oswaldo Cruz Foundation, concerning the evaluation of antimicrobial activity of disinfectants, the present investigation analyzed disinfectant products of general use which are available in the Brazilian market. Of the disinfectants randomly collected, three of them (products A, B and C) showed microbial contamination. The contaminant microorganisms isolation and identification were performed by using the equipment $V_{\text {itek }}{ }^{\circledR} 2$, and the rRNA 16S amplification and sequencing were done. Vitek ${ }^{\circledR}$ analysis revealed the occurrence of Serratia marcescens and Achromobacter xylosoxidans in the products A and B, respectively. Aeromonas salmonicida was detected by Vitek ${ }^{\circledR}$, and Burkholderia lata was identified by means of amplification technique through polymerase chain reaction in the product $\mathrm{C}$.
\end{abstract}

Keywords. microbial contamination, disinfectants, quality control, sanitary surveillance. 


\section{INTRODUÇÃO}

Contaminação microbiana tem sido encontrada em diversos produtos desinfetantes desde a década de 1970, quando as práticas relacionadas ao controle da qualidade do processo de produção ainda eram pouco regulamentadas e distantes dos conceitos atuais. Nos últimos 30 anos, vários relatos na literatura demonstraram a presença de bactérias como contaminantes de produtos desinfetantes, como o isolamento de Serratia marcescens em clorexidina ${ }^{1}$, Pseudomonas aeruginosa e Pseudomonas cepacia em soluções à base de iodo ${ }^{2,3}$. Particularmente nos produtos desinfetantes constituídos de compostos quaternários de amônio, existem relatos na literatura que demonstraram a presença de diversas espécies bacterianas, contaminando esses tipos de produtos, como Burkholderia cepacia, Serratia marcescens, Pseudomonas aeruginosa e Alcaligenes xylosoxidans. Em um desses relatos, pesquisadores de um hospital no Japão estudaram a presença de contaminação microbiana em objetos e soluções utilizados para o processo de lavagem e desinfecção, evidenciando a presença dos gêneros Burkholderia e Pseudomonas ${ }^{4}$.

A presença de produtos com contaminação microbiana representa um tema de grande importância para saúde pública, uma vez que patógenos presentes nesses produtos podem causar infecções na população. No ambiente hospitalar, já foram descritos casos de surtos de infecções hospitalares causados por contaminação de dispensadores e soluções utilizadas como desinfetantes. Em um desses estudos, foi investigada a causa de um surto de $P$. aeruginosa num hospital na Itália, onde foi observada a contaminação por essa bactéria em dispensadores de sabonetes utilizados nos processos de antissepsia no hospital; foi evidenciada a possível contaminação dessas soluções ou da superfície de contato com as mãos como uma potencial causa de infecções hospitalares ${ }^{5}$. Essa realidade torna-se muito preocupante quando esses patógenos são introduzidos no ambiente domiciliar através da utilização de produtos que teriam como principal função a eliminação dos mesmos. O ambiente domiciliar possui diversas fontes de contaminação microbiana, sendo um dos principais locais de transmissão de doenças infecciosas ${ }^{6}$. Nesses locais, uma série de objetos apresenta contaminação por microrganismos. Ojima e colaboradores estudaram 5 residências no Japão, pesquisando a presença de microrganismos em diferentes superfícies. A cozinha foi o local com maior contaminação por bactérias aeróbias, seguido pelo banheiro. Coliformes foram encontrados na geladeira, mais precisamente, no compartimento onde são estocados os vegetais. Escherichia coli, S. aureus e $P$. aeruginosa foram detectadas em diversas superfícies, como: torneiras, pias, esponjas, toalhas de prato e mão, maçanetas, brinquedos, dentre outros ${ }^{7}$. Também já foi demonstrada a presença de contaminação em locais de livre circulação, como: shoppings, aeroportos, corrimão de escadas, banheiros públicos, pontos de ônibus, telefones públicos e locais de recreação infantil ${ }^{8}$. Nesse contexto, a utilização de produtos desinfetantes no controle da presença de microrganismos nesses ambientes se torna uma importante ferramenta na prevenção de doenças infecciosas desde que livres de contaminação. Dessa forma, a comercialização de desinfetantes com infecção microbiana coloca em risco diretamente a saúde da população.

Assim, a identificação dos microrganismos envolvidos na contaminação dos produtos se mostra um recurso de grande utilidade para auxiliar no monitoramento da fonte de contaminação durante o processo de fabricação, uma vez que as características dos microrganismos envolvidos podem indicar a porta de entrada destes na linha de produção industrial, além de alertar a população em geral sobre o potencial risco na utilização de produtos desinfetantes contaminados. Existem diferentes técnicas disponíveis para a identificação de amostras microbianas. A realização de provas bioquímicas para a observação do perfil fenotípico é uma ferramenta recorrente e, nesse contexto, existem alguns equipamentos de identificação microbiana que são capazes de otimizar essa avaliação. Com o avanço tecnológico, foram também desenvolvidas técnicas moleculares para a avaliação do perfil genotípico das amostras, possibilitando a identificação de microrganismos através da amplificação de genes pela reação em cadeia da polimerase (Polimerase Chain Reaction - PCR) e posterior sequenciamento dos amplicons. Assim, diferentes ferramentas são utilizadas, levando a maior precisão de identificação e melhor monitoramento do processo de fabricação com o intuito de gerar produtos de qualidade, que não coloquem em risco a saúde dos consumidores ${ }^{9}$.

Dessa forma, o objetivo desse trabalho foi o reconhecimento dos contaminantes presentes em três produtos desinfetantes à base de compostos quaternários de amônio adquiridos no mercado brasileiro. Esses 
produtos faziam parte de um estudo que o Setor de Saneantes do Departamento de Microbiologia do Instituto Nacional de Controle de Qualidade em Saúde da Fundação Oswaldo Cruz estava realizando, envolvendo a avaliação da atividade antimicrobiana de produtos desinfetantes de uso domiciliar e institucional.

\section{MATERIAL E MÉTODOS}

Foram utilizados nesse trabalho três produtos à base de quaternários de amônio dispostos à venda no mercado brasileiro (produtos A, B e C). A avaliação do teor de princípio ativo dos produtos foi realizada pelo Setor de Saneantes e Cosméticos do Departamento de Química do INCQS, de acordo com o POP INCQS nº 65.3110.014 ${ }^{10}$.

Para verificação da presença de contaminação microbiana, foi realizada a inoculação de alíquotas de 1 $\mathrm{mL}$ retiradas diretamente da embalagem dos produtos em $10 \mathrm{~mL}$ de caldo Letheen, esses tubos foram incubados por 7 dias a $37^{\circ} \mathrm{C}$. A partir destes tubos apresentando crescimento microbiano, foram realizados o isolamento do crescimento, através da semeadura por esgotamento nos meios de cultura Trypticase Soy Agar (TSA), Ágar Cetrimida e Ágar Lovestein-Jensen, e a bacterioscopia das culturas pelo método de coloração de Gram para a verificação das características morfotintoriais desses contaminantes. A identificação das bactérias contaminantes foi realizada utilizando-se o equipamento Vitek $^{\otimes} 2$ (bioMérieux), que realiza uma série de provas bioquímicas a partir da cultura isolada das amostras. Alçadas do microrganismo isolado foram retiradas para a obtenção de uma suspensão 0,5 em escala MacFarland e em solução salina $0,85 \%$. A suspensão foi utilizada no aparelho em um cartão de identificação (Cartão Vitek 2 GN, no lote: 241188540) relativo ao Gram confirmado pela bacterioscopia.

Além disso, foi realizada a extração do DNA, pela fervura e posterior congelamento de alíquotas do crescimento microbiano das amostras isoladas em meio TSA. Após a etapa de extração de DNA, foi realizada a PCR para a amplificação do gene rRNA 16S, descrito por Watts e colaboradores9. Para a amostra contaminante dos produtos A e B, a PCR foi realizada nas seguintes condições: $10 \mu \mathrm{L}$ de tampão TE (1x), $1 \mu \mathrm{L}$ de magnésio (2 $\mathrm{mM}), 2 \mu \mathrm{L}$ de $\mathrm{dNTP}(10 \mathrm{mM}), 0,5 \mu \mathrm{L}$ de cada primer (50 ng), $0,5 \mu \mathrm{L}$ de Taq polimerase, $1,5 \mu \mathrm{L}$ do DNA da amostra do produto $\mathrm{A}, 1 \mu \mathrm{L}$ do DNA da amostra do produto B, e água (para $50 \mu \mathrm{L}$ ). A ciclagem da reação foi realizada nas seguintes condições: $94{ }^{\circ} \mathrm{C}$ por 2 minutos; $94{ }^{\circ} \mathrm{C}$ por 1 minuto, $52^{\circ} \mathrm{C}$ por 1 minuto, $72{ }^{\circ} \mathrm{C}$ por 2 minutos (esses três últimos passos foram realizados por 30 ciclos); $72{ }^{\circ} \mathrm{C}$ por 7 minutos; e $4{ }^{\circ} \mathrm{C}$ sem tempo determinado. Para a amostra contaminante do produto $\mathrm{C}$, a PCR foi executada nas seguintes condições: $10 \mu \mathrm{L}$ de tampão TE (1x), $3 \mu \mathrm{L}$ de magnésio $(3 \mathrm{mM}), 2 \mu \mathrm{L}$ de $\mathrm{dNTP}(10 \mathrm{mM})$, $0,5 \mu \mathrm{L}$ de cada primer $(50 \mathrm{ng}), 0,5 \mu \mathrm{L}$ de Taq polimerase, $4 \mu \mathrm{L}$ do DNA da amostra e água (para $50 \mu \mathrm{L}$ ). A ciclagem da reação foi feita nas seguintes condições: $94^{\circ} \mathrm{C}$ por 2 minutos; $94^{\circ} \mathrm{C}$ por 1 minuto, $50{ }^{\circ} \mathrm{C}$ por 1 minuto, $72{ }^{\circ} \mathrm{C}$ por 2 minutos (esses três últimos passos foram realizados por 35 ciclos); $72{ }^{\circ} \mathrm{C}$ por 7 minutos; e $4{ }^{\circ} \mathrm{C}$ sem tempo determinado.

Os produtos obtidos pela PCR foram purificados com o kit Pure Link PCR Purification (Invitrogen). Foram adicionados $172 \mu \mathrm{L}$ de tampão de ligação a $40 \mu \mathrm{L}$ do amplificado do produto $\mathrm{C}$ e $50 \mu \mathrm{L}$ do amplificado dos produtos $\mathrm{A}$ e $\mathrm{B}$, em tubos do kit contendo resina de purificação. Após centrifugação a 11.000 rpm por 1 minuto, o sobrenadante foi descartado e foram adicionados 650 $\mu \mathrm{L}$ de tampão de lavagem. Após duas centrifugações a $11.000 \mathrm{rpm}$ por 1 minuto, o sobrenadante foi descartado e foram adicionados $50 \mu \mathrm{L}$ de tampão de eluição, o qual ficou no tubo a temperatura ambiente por 50 minutos. Após esse tempo, o tubo foi centrifugado a $11.000 \mathrm{rpm}$ por 1 minuto e, posteriormente, a resina foi descartada e o sobrenadante foi guardado em refrigerador a $-4^{\circ} \mathrm{C}$.

Os produtos de PCR purificados foram utilizados como molde de DNA para a reação de sequenciamento de suas duas fitas com o sistema comercial BigDye Terminator Cycle Sequencing Kit (Applied Biosystems), conforme as recomendações do fabricante. Após a etapa de sequenciamento, as sequências nucleotídicas foram analisadas, editadas e comparadas a sequências depositada no GenBank.

\section{RESULTADOS}

A análise química do teor dos produtos revelou que os três desinfetantes utilizados no trabalho estavam fora dos padrões em relação ao teor do princípio ativo, apresentando $24 \%$, $20 \%$ e $68 \%$ acima do declarado pelos fabricantes nos produtos $\mathrm{A}, \mathrm{B}$ e $\mathrm{C}$, respectivamente.

A avaliação da bacterioscopia das amostras revelou a presença de bastonetes Gram-negativos como contaminantes de todos os três produtos. Através 
da utilização do equipamento Vitek $^{\oplus}$ 2, foi revelada a presença de Serratia marcescens, Achromobacter xylosoxidans e Aeromonas salmonicida nos produtos A, $\mathrm{B}$ e C, respectivamente, todas com $99 \%$ de probabilidade (Tabela). No sequenciamento do gene rRNA $16 \mathrm{~S}$ das amostras, foi revelada a presença de Serratia marcescens com 99,79\% de homologia, Achromobacter insolitus com 98,73\% de homologia e Burkholderia lata com 99,93\% de homologia nos produtos A, B e C, respectivamente (Tabela). A amplificação de outros genes é necessária para a exata identificação das espécies.

Tabela. Bactérias encontradas como contaminantes dos produtos A, B e C identificadas através do Vitek 2 e do sequenciamento do gene rRNA 16S

\begin{tabular}{ccc}
\hline Produtos & Vitek $^{\circledR} 2$ & $\begin{array}{c}\text { Sequenciamento gene } \\
\text { rRNA 16S }\end{array}$ \\
\hline A & Serratia marcescens & Serratia marcescens $(99,79 \%)$ \\
B & Achromobacter & Achromobacter insolitus \\
C & Aeromonas salmonicida & Burkholderia lata $(99,93 \%)$ \\
\hline
\end{tabular}

\section{DISCUSSÃO}

Os resultados desse trabalho permitiram observar a existência de contaminação microbiana em produtos desinfetantes dispostos à venda no mercado brasileiro nos dias atuais, corroborando com dados da literatura que mostram a ocorrência desse tipo de desvio de qualidade desde a década de $1970^{4}$. Essas observações chamam a atenção para um sério problema de saúde pública, uma vez que esses produtos, ao invés de estarem eliminando os microrganismos e garantindo a saúde da população, estão, na verdade, introduzindo bactérias e, possivelmente, patógenos em residências, ambientes de atendimento à saúde e em indústrias, gerando um grave risco à saúde de toda a população. A maior tolerância dessas bactérias encontradas como contaminantes de produtos desinfetantes parece estar relacionada a uma adaptação fisiológica em resposta a mudança no ambiente, principalmente com alterações na membrana externa das células. Em $P$. aeruginosa, observou-se que há uma diferença na composição do lipopolissacarídeo (LPS) e aumento no conteúdo do íon $\mathrm{Mg}+$, que fortalece as ligações entre os LPS. Além da presença de porinas de baixa eficiência que impedem a difusão de moléculas para o interior da célula. Em B. cepacia, o alto conteúdo de arabinose ligado ao fosfato no seu LPS parece diminuir a afinidade da membrana externa em relação às moléculas catiônicas ${ }^{11}$. Nesse contexto, a introdução de bactérias com maior tolerância a esses produtos nos ambientes domiciliar e hospitalar torna ainda mais preocupante a ocorrência de surtos causados por essas bactérias, uma vez que elas podem possuir um maior perfil de tolerância a agentes antimicrobianos, podendo causar infecções que necessitem de controle e tratamentos mais complexos.

Apesar da grande importância desse assunto para a saúde pública, são encontrados poucos relatos na literatura de produtos contaminados sendo comercializados no mercado brasileiro, principalmente no âmbito domiciliar. Nossos dados representam uma das poucas demonstrações de contaminação encontrada diretamente da embalagem de produtos desinfetantes de uso geral, uma vez que a maioria dos trabalhos da literatura relata casos de contaminação de produtos no ambiente hospitalar.

Além da presença de contaminantes nas formulações dos produtos, foi observado o desvio de qualidade em relação à análise química do teor de princípio ativo, indicando que atualmente, apesar da alta tecnologia, processos de fabricação padronizados e rastreados, e um rígido sistema de controle de qualidade, ainda assim é possível encontrar falhas no processo de fabricação, gerando desvios na qualidade dos produtos industriais. Esses dados indicam a necessidade de haver um intenso controle, por parte das próprias empresas, de todas as etapas do processo de fabricação, além da avaliação de todos os lotes de produto final. Além disso, apesar da legislação brasileira não prever a avaliação da presença de possíveis contaminantes, se faz necessária também, uma severa fiscalização pelos órgãos responsáveis para que não cheguem ao mercado produtos com desvios de qualidade que possam gerar risco à saúde ${ }^{12}$.

Dessa forma, no âmbito das indústrias, fazer uso da identificação dos microrganismos presentes como contaminantes em cada etapa do processo de fabricação é uma ferramenta muito útil para monitorar os principais pontos críticos da linha de produção. Além disso, o conhecimento das espécies microbianas envolvidas com as contaminações do processo de fabricação ajuda a identificação da porta de entrada desse contágio, por meio da avaliação das características e comportamento dos microrganismos em questão, associando-os a fonte de contaminação que podem ser a água, matéria-prima e, até mesmo, o ambiente fabril. No âmbito dos órgãos 
de fiscalização, a identificação desses microrganismos auxilia o rastreamento de surtos possivelmente causados por essas contaminações, além de permitir uma avaliação mais completa dos produtos.

Esse trabalho permitiu identificar os contaminantes de produtos desinfetantes por duas abordagens diferentes: uma, por meio de uma série de provas bioquímicas realizadas pelo equipamento Vitek $^{\circledR} 2$; outra, através da amplificação e sequenciamento do gene rRNA 16S, importante gene utilizado para a identificação de microrganismos. Para os produtos A e B, as duas abordagens apresentaram resultados muito semelhantes, entretanto para o produto $\mathrm{C}$, a identificação microbiana se apresentou diferente, indicando que a identificação baseada em provas bioquímicas nem sempre corrobora com a apoiada em estudos moleculares. Por isso, para uma identificação mais precisa das espécies envolvidas na contaminação dos produtos, é necessário o estudo de outros genes conservados capazes de gerar dados para essa distinção.

Assim, a presença de desvios na qualidade dos produtos industrializados que possam resultar em riscos à saúde da população deve ser evitada por meio de um rígido controle dos processos de fabricação, minimizando possíveis falhas e mantendo o produto final seguro para ser comercializado.

\section{CONCLUSÃO}

Esse trabalho permitiu concluir que a identificação de contaminantes em produtos desinfetantes comercializados no mercado brasileiro, indica a presença de desvios na qualidade que podem gerar graves riscos à saúde da população. Com isso, é possível perceber a importância de se ter um rígido sistema de avaliação da qualidade desses produtos, tanto por parte das empresas, como dos órgãos responsáveis pela fiscalização.

Assim, a notificação e atenção voltada para os desvios de qualidade encontrados em produtos desinfetantes presentes no mercado é de extrema importância para a prevenção e redução de riscos à saúde pública.

\section{AGRADECIMENTOS}

Ao Instituto Nacional de Controle de Qualidade em Saúde (INCQS), pelo apoio financeiro e estrutural. À Coordenação de Aperfeiçoamento de Pessoal de Nível Superior (Capes), pelo apoio financeiro (bolsa mestrado). Agradecemos o Laboratório de Saneantes e Cosméticos do INCQS pelas análises dos produtos saneantes

\section{REFERÊNCIAS}

1. Marrie TJ, Costerton JW. Prolonged survival of Serratia marcescens in chlorhexidine. Appl Environ Microbiol. 1981;42:1093-102.

2. Berkelman RL, Anderson RL, Davis BJ, Highsmith AK, Petersen $\mathrm{NJ}$, Bond WW, et al. Intrinsic bacterial contamination of a commercial iodophor solution: investigation of the implicated manufacturing plant. Appl Environ Microbiol. 1984;47:752-6.

3. Anderson RL, Vess RW, Panlilio AL, Favero MF. Prolonged survival of Pseudomonas cepacia in commercially manufactured povidone-iodine. Appl Environ Microbiol. 1990;56:3598-600.

4. Oie S, Kamiya A. Microbial contamination of antiseptics and disinfectants. Am J Infect Control. 1996;24:385-95.

5. Lanini S, D’Arezzo S, Puro V, Martini L, Imperi F, Piselli P, et al. Molecular epidemiology of a Pseudomonas aeruginosa. Hospital outbreak driven by a contaminated disinfectant-soap dispenser. PLoS ONE. 2011;6(2):e17064 /journal.pone.0017064.

6. Kagan LJ, Aiello AE, Larson E. The role of the home environment in the transmission of infectious diseases. J Community Health. 2002;27:247-64.

7. Ojima M, Toshima Y, Koya E, Ara K, Tokuda H, Kawai S, et al. Hygiene measures considering actual distributions of microorganisms in Japanese households. J Appl Microbiol. 2002;93:800-9.

8. Reynolds KA, Watt PM, Boone SA, Gerba CP. Occurrence of bacteria and biochemical markers on public surfaces. Int. J Environ Health Res. 2005;15(3):225-34.

9. Watts JL, Lowery DE, Teel JF, Rossbach S. Identification of Corynebacterium bovis and other coryneforms isolated from bovine mammary glands. J Dairy Sci. 2000;83(10):2373-9.

10. Instituto Nacional de Controle de Qualidade em Saúde. Manual da Qualidade. Determinação de Tensoativos Aniônicos e Catiônicos. Rev. 10. In: Manual da Qualidade. Rio de Janeiro: INCQS/FIOCRUZ, 2011. Seção 4.3. 9 p. (65.3110.014 rev. 10).

11. Timenetsky J. Avaliação microbiológica de desinfetantes químicos de uso doméstico. Rev Saúde Pública. 1990;24:47-50.

12. Mcdonnell G, Russell AD. Antiseptics and Disinfectants: Activity, Action, and Resistance. Clin Microbiol Rev. 1999;12(1):147-79. 